\title{
Normal lumbar bone mineral density in optimally treated children and young adolescents with 6 -thalassaemia major
}

\author{
Athanasios Christoforidis, ${ }^{1}$ Eirini Kazantzidou, ${ }^{2}$ Ioanna Tsatra, ${ }^{1}$ Haido Tsantali, ${ }^{1}$ \\ George Koliakos, ${ }^{3}$ Emmanouil Hatzipantelis, ${ }^{1}$ George Katzos, ${ }^{1}$ \\ Miranda Athanassiou-Metaxa ${ }^{1}$
}

${ }^{1}$ Thalassaemia Unit, $1^{\text {st }}$ Paediatric Department, Aristotle University of Thessaloniki, ${ }^{1}$ Radiology Department Hippokration General Hospital of Thessaloniki, ${ }^{2}$ Department of Biological Chemistry, Medical School, Aristotle University of Thessaloniki

\begin{abstract}
OBJECTIVE: Osteopenia/osteoporosis of multi-factorial pathogenetic mechanism is reported to be a significant cause of morbidity in adult patients with $\beta$-thalassaemia major. Even in young patients, decreased Bone Mineral Density (BMD) values are a consistent finding in the literature. This study was performed in order to assess BMD in children and young adults with $\beta$-thalassaemia major, regularly transfused and sufficiently chelated, along with auxological, clinical and laboratory parameters. DESIGN: Thirty-five young thalassaemic patients (19 F, $16 \mathrm{M}$, aged 5-20 yr) were studied. Lumbar BMD was assessed by dual X-ray absorptiometry (DXA) and Z-scores were calculated according to bone density values using age- and sex-matched normal population. None of the patients presented with clinical or laboratory signs of endocrinopathy and none was receiving hormonal replacement therapy. RESULTS: All BMD Z-scores were within normal range, with a mean $\mathrm{Z}$-score of 0.42 for girls and $\mathbf{- 0 . 4 1}$ for boys (statistically significant gender difference, $p=0.018$ ). When correlated with age, a decline in Z-scores was observed, indicating a delay in bone mass acquisition with advancing age in the thalassaemic group compared to controls. CONCLUSIONS: Optimal conventional treatment prevents the manifestation of osteopenia/osteoporosis during the first two decades of life in patients with $\beta$-thalassaemia major. However, close surveillance with regular screening, preventive intervention and early management of possible endocrine complications are essential in order to secure normal bone health during adulthood and improve quality of life in the thalassaemic population.
\end{abstract}

Key words: Bone Mineral Density (BMD), $\beta$-thalassaemia major, Children, DXA, IGF-1, IGFBP-3, Osteopenia, Osteoporosis 


\section{INTRODUCTION}

$\beta$-thalassaemia major represents a heamoglobinopathy caused by a hereditary defect in the synthesis of beta chain in adult haemoglobin, which results in ineffective erythropoiesis and increased peripheral haemolysis. Conventional management of $\beta$-thalassaemia major requires regular blood transfusions in order to maintain pre-transfused Haemoglobin $(\mathrm{Hb})$ levels between $9-10 \mathrm{~g} / \mathrm{dl}$ and adequate chelation therapy with desferrioxamine, deferiprone or a combination of these two drugs. In this way, bone deformations and endocrine complications, particularly during childhood and adolescence, are prevented and normal growth and puberty are ensured.

Osteoporosis is reported to be an important cause of morbidity in adult patients with thalassaemia major. ${ }^{1}$ The pathogenesis of osteoporosis in thalassaemic patients is multi-factorial: 1) Bone marrow expansion due to ineffective erythropoiesis results in reduction of trabecular bone tissue with additional cortical thinning and increased distortion and fragility of the bones; ${ }^{2}$ 2) endocrine dysfunction consisting mainly of hypogonadism and additionally hypothyroidism, hypoparathyroidism, diabetes mellitus as well as an impaired GH-IGF-I axis resulting in decreased bone formation and increased bone resorption; 33 ) iron deposition plays a major role in the pathogenesis of osteoporosis as it is the prime cause for endocrine gland dysfunction; moreover, iron deposition directly in the bone impairs osteoid maturation and inhibits mineralization locally resulting in focal osteomalakia; ${ }^{4}$ 4) chelation therapy with desferrioxamine is considered to inhibit DNA synthesis, osteoblast and fibroblast proliferation, osteoblast precursor's differentiation and collagen formation, whereas in high doses it enhances osteoblast apoptosis; ${ }^{5} 5$ ) reduced physical activity as a result of the disease's complications and parental over-protectiveness in children and adolescents with thalassaemia major reduces optimal bone mineralization.

Our aim was to evaluate bone mineral density in children and adolescents with $\beta$-thalassaemia major in relation to clinical, biochemical and hormonal parameters.

\section{SUBJECTS AND METHODS}

Thirty-five children and young adults with $\beta$ thalassaemia major (19 females and 16 males) were enrolled in this study. Ages ranged from 5 to 20 years with a mean age of 12.7 years. All patients underwent regular blood transfusions in order to maintain pretransfused $\mathrm{Hb}$ concentrations above $9 \mathrm{~g} / \mathrm{dl}$. Chelation therapy included desferrioxamine, deferiprone or a combination of these two drugs.

Regarding auxological and pubertal status, all patients were assessed by the same investigator (A.C.) and Standard Deviation Scores (SDS) for height, weight and Body Mass Index (BMI) were calculated according to sex- and age-matched reference data from the normal Greek population. ${ }^{6}$ None of the patients presented with any endocrine disorder or was receiving any kind of hormonal replacement therapy. Bone age was assessed from hand X-rays evaluated twice by the same investigator (A.C.), using the RUS (TW3) method. ${ }^{7}$

Mean bone mineral density of the lumbar vertebrae (L2 - L4) was assessed by dual X-ray absorptiometry technique (DXA) using Cronos $^{\circledR}$ DMS $^{\circledR}$ bone densitometer (France). Results were expressed as grams per centimeter squared $\left(\mathrm{g} / \mathrm{cm}^{2}\right)$, whilst Z-scores were calculated based on BMD of normal age- and sex-matched Caucasian population provided by the manufacturer of the DXA device.

Serum IFG-I and IGFBP-3 levels were measured by Immunoradiometric Assay (IRMA) using reagents purchased from Diagnostic Systems Laboratories ${ }^{\circledR}$, Texas, USA. Sensitivity, intra-assay Coefficients of Variation (CV) and inter-assay CV for IGF-I assay were $0.03 \mathrm{ng} / \mathrm{ml}, 4.5-7.1 \%$ and $4.8-8.8 \%$, respectively, whereas for IGFBP-3 assay they were 0.04 $\mathrm{ng} / \mathrm{ml}, 7.3-9.6 \%$ and $8.2-11.4 \%$, respectively. Intact Parathormone (PTH) and thyroid function (FT4, FT3 and TSH) were evaluated using commercial Radioimmunoassay (RIA) methods. Concentrations of serum Calcium (Ca), Phosphate $(\mathrm{P})$ and Alkaline Phosphatase (ALP) were assessed by established methodology. Serum ferritin concentrations were measured every trimester during the past year using a Microparticle Enzyme Immunoassay (MEIA), and 
mean ferritin value was calculated for each patient.

Normality of distribution of the studied parameters was assessed with the One-Sample Komgorov-Smirnof test. Normally distributed parameters were then compared with Student's t-test, whilst correlations between studied parameters were assessed with Pearson's $r$ function. A p value less than 0.05 was considered as statistically significant. SPSS ${ }^{\circledR}$ for Windows ver.11.5.0 and Microsoft ${ }^{\circledR}$ Office Excel 2003 software programs were employed for statistical analysis and graphical demonstration.

\section{RESULTS}

Results regarding the auxological status of the patients are shown in Figure 1 and are summarized in Table 1. Fourteen out of the 19 females $(74 \%)$ and 11 out of the 16 males (69\%) were shorter than average. Mean height SD scores were -0.32 and -0.42 , respectively. By contrast, 16 out of the 19 females $(84 \%)$ and 11 out of the 16 males (69\%) had BMI values higher than the average. Mean BMI SD scores were 0.61 and 0.8 , respectively. Most of the patients had delayed bone age $(20 / 35,57.1 \%)$ with an average SDS of -0.39 , but only 5 of them had SDS less than -2. None of the patients had any clinical sign of endocrinopathy or presented with any kind of pubertal disorder. Biochemical profile, intact PTH concentrations and thyroid function tests were normal in every patient. IGF-I mean SDS for the girls was $-0.35 \pm 0.95$, whereas mean SDS for the boys was $0.14 \pm 0.82$. IGFBP- 3 mean SDS for the girls was $-0.06 \pm 0.64$, whereas for the boys it was $-0.09 \pm 0.64$. Mean ferritin levels ranged from $242 \mu \mathrm{g} / \mathrm{L}$ to 4706 $\mu \mathrm{g} / \mathrm{L}$ with an average of $1393 \pm 804 \mu \mathrm{g} / \mathrm{L}$.

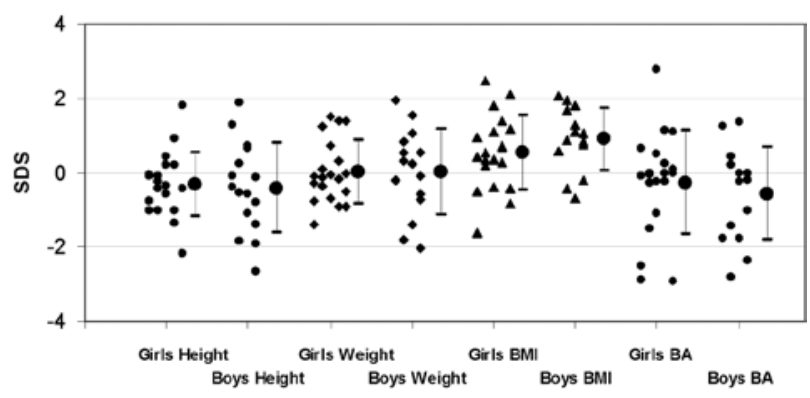

Figure 1. SD scores of height, weight, Body Mass Index (BMI) and Bone Age (BA) in girls and boys.
Table 1. Auxological data of thalassaemic patients.

\begin{tabular}{lccc}
\hline Parameter & $\begin{array}{c}\text { Girls } \\
(\mathbf{n = 1 9})\end{array}$ & $\begin{array}{c}\text { Boys } \\
(\mathbf{n = 1 6})\end{array}$ & $\begin{array}{c}\text { Both sexes } \\
(\mathbf{n = 3 5})\end{array}$ \\
\hline Age & & & \\
Mean \pm SD & $12.78 \pm 4.07$ & $12.75 \pm 3.37$ & $12.78 \pm 3.71$ \\
Range & $5-20.5$ & $5.5-20$ & $5-20.5$ \\
Height SDS & & & \\
Mean \pm SD & $-0.32 \pm 0.82$ & $-0.42 \pm 1.17$ & $-0.36 \pm 0.97$ \\
Range & $-2.17-1.8$ & $-2.66-1.88$ & $-2.66-1.88$ \\
Weight SDS & & & \\
Mean \pm SD & $0.1 \pm 0.83$ & $-0.04 \pm 1.14$ & $0.02 \pm 0.97$ \\
Range & $-1.38-1.51$ & $-2.0-1.95$ & $-2.0-1.95$ \\
BMI SDS & & & \\
Mean \pm SD & $0.61 \pm 0.65$ & $0.8 \pm 0.71$ & $0.69 \pm 0.69$ \\
Range & $-1.63-2.48$ & $-0.84-2.12$ & $-1.63-2.48$ \\
Bone Age SDS & & & \\
Mean \pm SD & $-0.28 \pm 1.42$ & $-0.52 \pm 1.22$ & $-0.39 \pm 1.32$ \\
Range & $-2.92-2.78$ & $-2.81-1.36$ & $-2.92-2.78$ \\
\hline
\end{tabular}

All BMD results were within the normal range (Figure 2). The mean lumbar BMD Z-score was $0.42 \pm 1.25$ for the females, $-0.41 \pm 0.95$ for the males (statistically significant difference between sexes; $\mathrm{p}=0.034$ ) and $0.04 \pm 1.19$ for the entire group of patients. None of the patients was in the osteoporotic range (Z-score <-2.5), whereas only 1 out of the 19 girls $(5.26 \%)$ and 6 out of the 16 boys $(37.5 \%)$ were in the osteopenic range (-1> Z-score $>-2.5)$. Mean values and ranges of serum IGF-I and IGFBP-3 concentrations SDS, serum ferritin levels and lumbar BMD SDS are presented in Table 2. When correlated with age, lumbar BMD Z-scores showed a markedly linear regression, $\left(r=0.467, r^{2}=0.218, p=0.05\right.$, Figure $3)$. No correlation was observed between lumbar BMD and mean annual ferritin levels $(r=0.242$, $\mathrm{p}=0.162$, Figure 4), nor between lumbar BMD and serum IGF-I $(r=-0.109, p=0.532$, Figure 5), whereas a positive correlation was seen between lumbar BMD and IGFBP-3 circulating concentrations $(\mathrm{r}=0.354$, $p=0.037$, Figure 5). Finally, no correlation was observed between height SDS and lumbar BMD SDS $(r=0.264, p=0.126$, Figure 6).

\section{DISCUSSION}

Bone deformities were assigned as a characteristic 

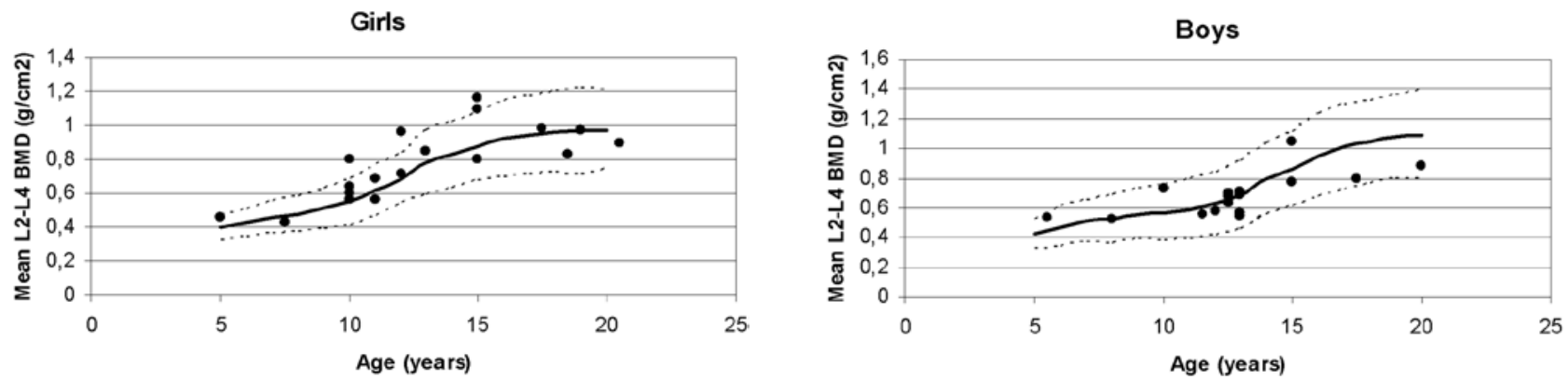

Figure 2. Mean lumbar Bone Mineral Density (BMD) plotted against normal values for age in girls and boys with $\beta$-thalassaemia.

Table 2. Levels of IGF-I, IGFBP-3, ferritin and BMD measurements in thalassaemic patients.

\begin{tabular}{lcccc}
\hline Parameter & $\begin{array}{c}\text { Girls } \\
(\mathbf{n = 1 9})\end{array}$ & $\begin{array}{c}\text { Boys } \\
(\mathbf{n = 1 6})\end{array}$ & $\mathbf{p}$ & $\begin{array}{c}\text { Total } \\
(\mathbf{n = 3 5})\end{array}$ \\
\hline IGF-I SDS & & & & \\
Mean \pm SD & $-0.35 \pm 0.95$ & $0.14 \pm 0.82$ & & $-0.13 \pm 0.91$ \\
Range & $-2.25-1.27$ & $-1.62-1.81$ & 0.109 & $-2.25-1.81$ \\
IGFBP-3 SDS & & & & \\
Mean \pm SD & $-0.06 \pm 0.64$ & $-0.09 \pm 0.64$ & & $-0.08 \pm 0.63$ \\
Range & $-0.95-1.35$ & $-0.95-1.17$ & 0.877 & $-0.95-1.35$
\end{tabular}

Serum ferritin

(ng/L)

Mean \pm SD

$1557 \pm 929 \quad 1199 \pm 594$

Range

$627-4706 \quad 242-2633$

$0.177 \begin{aligned} & 1393 \pm 804 \\ & 242-4706\end{aligned}$

Lumbar BMD

SDS

$\begin{array}{llccc}\text { Mean } \pm \text { SD } & 0.42 \pm 1.25 & -0.41 \pm 0.95 & & 0.04 \pm 1.19 \\ \text { Range } & -1.17-3.8 & -1.8-0.9 & 0.034 & -1.8-3.8\end{array}$

feature in thalassaemia by Coley and Lee in their original description of the disease. ${ }^{8}$ They were attributed to marrow expansion and consequent reduction of trabecular bone tissue and cortical thinning due to increased but ineffective haemopoiesis. In recent years, advances in transfusion management and chelation therapy have achieved an improvement in skeletal development and cosmetic bone appearance. However, despite optimal conventional treatment and lack of endocrine complications, low bone density is still reported in thalassaemic patients. ${ }^{9-11}$

There is controversy regarding the optimal method for assessing bone mass in the paediatric population. In this study, we assessed bone mineral density using

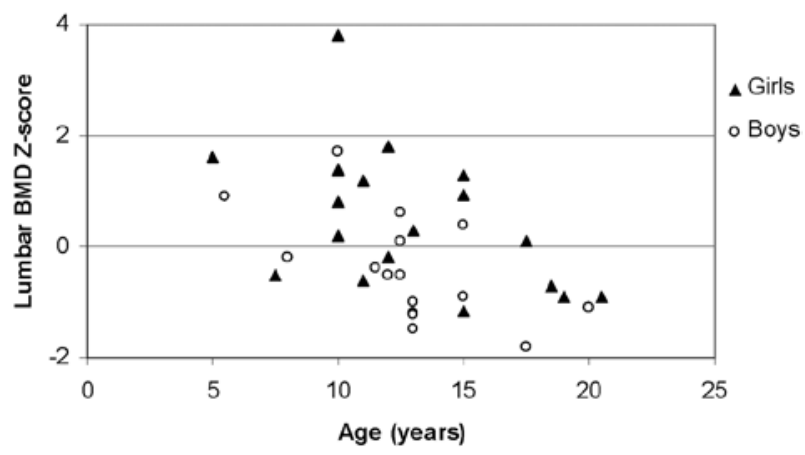

Figure 3. Correlation of lumbar BMD Z-scores with age $\left(\mathrm{r}=0.467, \mathrm{r}^{2}=0.218, \mathrm{p}=0.005\right)$.

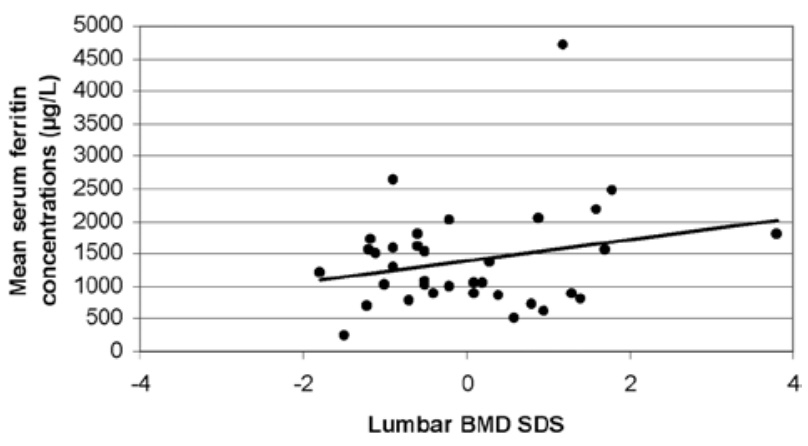

Figure 4. Correlation of lumbar BMD SD scores with mean serum ferritin concentrations $(r=0.242, p=0.162)$.

DXA, which still remains the most commonly used method. The advantages of this technique include the relatively low radiation exposure, its worldwide availability and the short duration of the procedure. Its main disadvantage is the fact that, as DXA is a 2-dimensional measurement, results are correlated to body and bone size, a factor which becomes more important in the growing paediatric population. In addition, significant differences among published 


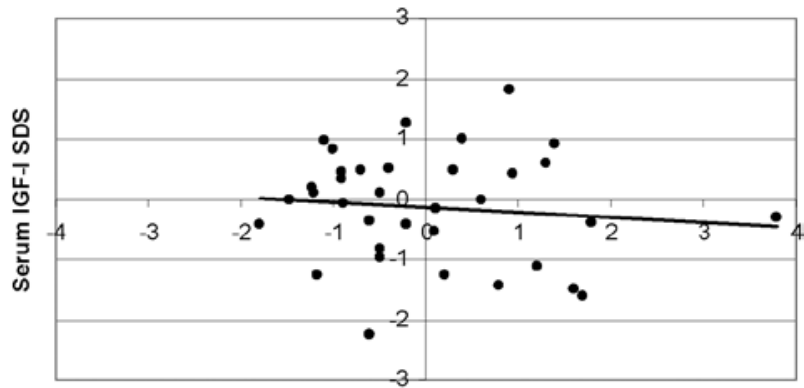

Lumbar BMD SDS

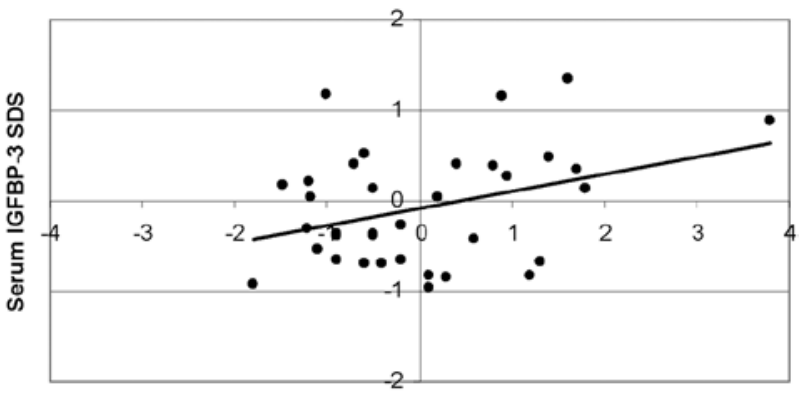

Lumbar BMD SDS

Figure 5. Correlation of serum IGF-I SD scores, serum IGFBP-3 SD scores with lumbar Bone Mineral Density (BMD) SD scores $(\mathrm{r}=-0.109, \mathrm{p}=0.532$ and $\mathrm{r}=0.354, \mathrm{p}=0.037$, respectively).

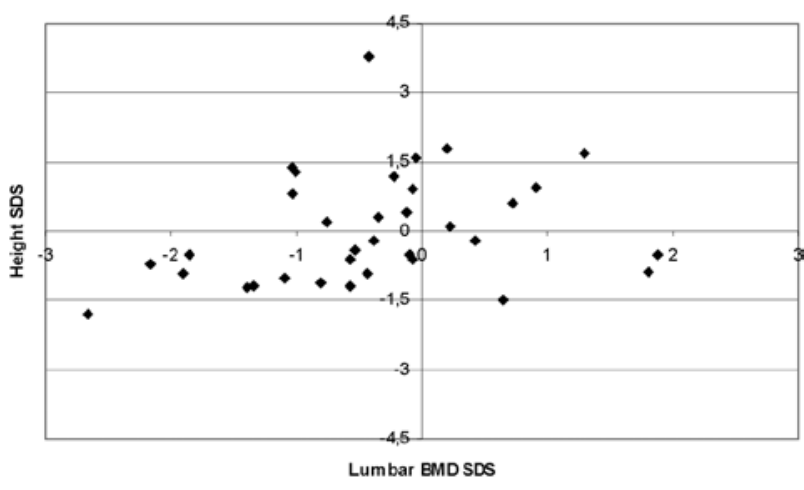

Figure 6. Correlation of height SD scores with lumbar BMD SD scores $(r=0.264, p=0.126)$.

paediatric reference data results in inconsistencies in the diagnosis of osteopenia among children with chronic diseases. ${ }^{12}$ An indirect validation of normal reference data used in our study was obtained by scanning the normal paediatric population (data are not shown). Quantitative Computed Tomography (QCT) is a relatively new 3-dimensional method which assesses cortical and trabecular bone separately. Its main disadvantage is the high radiation doses and the lack of normative paediatric reference database, as it is considered unethical to scan the healthy population. ${ }^{13}$ A study performed by Mylona et al compared these two methods in 48 patients with $\beta$-thalassaemia and the overall prevalence of osteoporosis was $44 \%$ with DXA but only 6\% with QCT. ${ }^{14}$ Finally, Quantitative UltraSonography (QUS) is a radiation-free alternative but still needs further research to improve the technique and prove its reliability. ${ }^{15}$

We limited the evaluation of bone mineral density in the lumbar vertebrae of thalassaemic patients. The lumbar spine, consisting mainly of trabecular bone, is mostly affected by bone marrow expansion due to increased and ineffective haemopoiesis occurring in patients with $\beta$-thalassaemia. In addition, as axial BMD increases more rapidly than peripheral BMD during puberty, ${ }^{16}$ pubertal disorders, frequently reported in thalassaemic patients, affect the lumbar spine to a higher degree than other sites. In a study performed by Mahachoklertwattana et al, BMD was evaluated in several sites in thalassaemic patients. ${ }^{17}$ Lumbar spine values were the lower ones, particularly in transfusion-dependent patients.

Of particular interest, although unexplained, were the statistically significant lower lumbar BMD values measured in the boys compared to the girls (Figure 2, Table 2). Moreover, this gender difference was more prominent in pubertal subjects participating in this study. Similar results regarding gender difference were reported in a study by Jansen et al. ${ }^{11}$ However, in that study, osteopenia/osteoporosis as well as pubertal disorders/hypogonadism had greater incidence. In our population, none was receiving hormonal replacement therapy and all pubertal patients have entered puberty spontaneously, whereas none of the pre-pubertal subjects was older than 10 years of age. Although delayed or arrested puberty is no longer seen in optimally treated thalassaemic patients, hypogonadism, a well-recognized cause of osteopenia/osteoporosis, remains the most common endocrinopathy. ${ }^{18}$ In a study performed in 67 Greek thalassaemic patients, a significant prevalence of low bone mass density was found, especially in patients presenting with hypogonadism. ${ }^{19} \mathrm{~A}$ 4-year followup study of 50 patients confirmed the increased 
prevalence of osteoporosis/osteopenia among the thalassaemic population but also indicated an improvement in bone mass in patients receiving sex steroid replacement therapy. ${ }^{20}$

Many studies have shown that although conventional therapy allows children to grow normally during the first decade of life, growth retardation is observed in a significant proportion during adolescence. ${ }^{21-24}$ These findings are consistent with our results, as mean height SDS were lower than the average of the sex and age-matched normal population (Figure 1). As DXA measurements are influenced by bone size, the small stature observed in the thalassaemic population has been postulated as contributing to decreased BMD..$^{25}$ However, advanced paediatric software adjusted to auxological parameters can overcome this obstacle. The role of locally expressed IGF-I as a potent stimulator of bone mineralization and growth has been described extensively in the literature. ${ }^{26}$ In 28 optimally treated adults with thalassaemia studied by Lasco et al in 2002, decreased BMD was correlated to low IGF-I and IGFBP-3 circulating concentrations. ${ }^{27}$ In our study, IGF-I and IGFBP-3 concentrations were not markedly decreased, indicating that adequate chelation therapy can preserve sufficient function of the GH-IGF-1axis and normal liver function, at least during the first two decades of life. An interesting study by Soliman et al compared 30 pre-pubertal children with $\beta$-thalassaemia with 15 children with constitutional short stature and pubertal delay. BMD values as well as IGF- I and IGFBP-3 serum concentrations were significantly lower in the thalassaemic group, ${ }^{28}$ indicating that delayed puberty and short stature alone could not explain low BMD in thalassaemic populations. In recent studies, scientific interest has been focused on genetic factors affecting bone mass acquisition. ${ }^{29,30}$ Although certain genes have been implicated in the pathogenesis of postmenopausal osteoporosis, they have not been studied thoroughly in thalassemia-induced osteoporosis. Wonke et al studied the Sp1 site of the collagen type Ia1 (COLIA 1) gene and found that approximately $30 \%$ of thalassaemic patients were heterozygotes (Ss), whereas $4 \%$ were homozygotes (SS). ${ }^{31}$

Studies referring to desferrioxamine-induced bone dysplasia in thalassaemic patients have been reported in the literature since the early 1990s. ${ }^{32,33}$
In a recent paper by Chan et al, radiographs of 41 children with homozygous $\beta$-thalassaemia were retrospectively reviewed. The radiographic findings showed an increased prevalence of thinned metacarpal cortices which, according to the authors, was due to desferrioxamine-induced bone dysplasia. ${ }^{34}$ In addition, desferrioxamine's possible interference with metals such as zinc or calcium may influence normal bone acquisition. During the last 5 years, a combination of desferrioxamine and deferiprone is mainly used as chelation therapy in our patients. This not only provides better synergistic chelation effects and enhances compliance but also reduces the dosedependent toxic effects of desferrioxamine.

Despite limitations of our study related to the limited number of patients and the lack of a paralel control group, our study is, to our knowledge, the first in the literature that shows normal BMD values in children with homozygous $\beta$-thalassaemia, regularly transfused and adequately chelated. Regression of marrow expansion due to regular transfusions, prevention of endocrine complications resulting in normal growth and pubertal development and reduction of desferrioxamine toxicity are the major contributors to this effect. In this way, low bone mineral density is not observed at least for the first two decades of life in patients with $\beta$-thalassaemia major. However, as thalassaemic patients are in greater risk of developing predisposing factors for osteoporosis, close surveillance and preventive intervention are essential. Regular screening and proper management of possible endocrine complications can possibly secure normal bone health, an extremely important consideration as life prolongation is nowadays an important achievement in patients with thalassaemia.

\section{REFERENCES}

1. Voskaridou E, Terpos E, 2004 New insights into the pathophysiology and management of osteoporosis in patients with beta thalassaemia. Br J Haematol 127: 127-139.

2. Vichinsky EP, 1998 The morbidity of bone disease in thalassemia. Ann N Y Acad Sci 850: 344-348.

3. Wonke B, 1998 Bone disease in beta-thalassaemia major. Br J Haematol 103: 897-901.

4. Mahachoklertwattana P, Sirikulchayanonta V, Chuansumrit A, et al, 2003 Bone histomorphometry in children and adolescents with beta-thalassemia disease: iron-associated focal osteomalacia. J Clin Endocrinol Metab 
88: 3966-3972.

5. De Sanctis V, Pinamonti A, Di Palma A, et al, 1996 Growth and development in thalassaemia major patients with severe bone lesions due to desferrioxamine. Eur J Pediatr 155: 368-372.

6. Papadimitriou A, Chiotis D, Tsiftis G, et al, 2002 Secular growth changes in the Hellenic population in the twentieth century. Hormones (Athens) 1: 245-250.

7. Tanner JM, Healy MJR, Goldstein H, Cameron N 2001 Assessment of skeletal maturity ( $3^{\text {rd }}$ edition). London: Harcourt Publishers Ltd; p, 110.

8. Cooley TB, Lee P, 1925 A series of cases of splenomegaly in children with anemia and peculiar bone change. Transactions of the American Pediatric Society 37: 29

9. Vogiatzi MG, Autio KA, Schneider R, Giardina PJ, 2004 Low bone mass in prepubertal children with thalassemia major: insights into the pathogenesis of low bone mass in thalassemia. J Pediatr Endocrinol Metab 17: 14151421.

10. Benigno V, Bertelloni S, Baroncelli GI, et al, 2003 Effects of thalassemia major on bone mineral density in late adolescence. J Pediatr Endocrinol Metab 16: Suppl 2: 337-342.

11. Jensen CE, Tuck SM, Agnew JE, et al, 1998 High prevalence of low bone mass in thalassaemia major. Br $\mathrm{J}$ Haematol 103: 911-915.

12. Leonard MB, Propert KJ, Zemel BS, Stallings VA, Feldman HI, 1999 Discrepancies in pedatric bone mineral density reference data: potential for misdiagnosis of osteopenia. J Pediatr 135: 182-188.

13. Specker BL, Schoenau E, 2005 Quantitative bone analysis in children: current methods and recommendations. J Pediatr 146: 726-731.

14. Mylona M, Leotsinides M, Alexandrides T, Zoumbos N, Dimopoulos PA, 2005 Comparison of DXA, QCT and trabecular structure in beta-thalassaemia. Eur J Haematol 74: 430-437.

15. Fielding KT, Nix DA, Bachrach LK, 2003 Comparison of calcaneus ultrasound and dual X-ray absorptiometry in children at risk of osteopenia. J Clin Densitom: Spring 6: 7-15.

16. Rubin K, Schirduan V, Gendreau P, Sarfarazi M, Mendola R, Dalsky G, 1993 Predictors of axial and peripheral bone mineral density in healthy children and adolescents, with special attention to the role of puberty. J Pediatr 123: 863-870.

17. Mahachoklertwattana P, Chuansumrit A, Sirisriro R, Choubtum L, Sriphrapradang A, Rajatanavin R, 2003 Bone mineral density, biochemical and hormonal profiles in suboptimally treated children and adolescents with beta-thalassaemia disease. Clin Endocrinol (Oxf) 58: 273-279.

18. No authors listed. Multicentre study on prevalence of endocrine complications in thalassaemia major, 1995 Italian Working Group on Endocrine Complications in Non-endocrine Diseases. Clin Endocrinol (Oxf) 42: 581-586.
19. Anapliotou ML, Kastanias IT, Psara P, Evangelou EA, Liparaki M, Dimitriou P, 1995 The contribution of hypogonadism to the development of osteoporosis in thalassaemia major: new therapeutic approaches. Clin Endocrinol (Oxf) 42: 279-287.

20. Molyvda-Athanasopoulou E, Sioundas A, Karatzas N, Aggellaki M, Pazaitou K, Vainas I, 1999 Bone mineral density of patients with thalassemia major: four-year follow-up. Calcif Tissue Int 64: 481-484.

21. Low LCK, 1997 Growth, puberty and endocrine function in beta-thalassaemia major. $\mathrm{J}$ Pediatr Endocrinol Metab10: 175-184.

22. Borgna-Pignatti C, Zurlo MG, DeStefano P, et al, 1993 Outcome of thalassemic treated with conventional therapy. Bone Marrow Transplantat 12: Suppl: 2-4.

23. De Sanctis V, Katz M, Vullo C, Bagni B, Ughi M, Wonke B, 1994 Effect of different treatment regimes on linear growth and final height in $\beta$-thalassaemia major. Clin Endocrinol 40: 791-798.

24. Raiola G, Galati MC, De Sanctis V, et al, 2003 Growth and puberty in thalassemia major. J Pediatr Endocrinol Metab 16: Suppl 2: 259-266.

25. Seeman E, 1998 Growth in bone mass and size are racial and gender differences in bone mineral density more apparent than real? J Clin Endocrinol Metab 83: 14141419.

26. Ueland T, 2005GH/IGF-I and bone resorption in vivo and in vitro.Eur J Endocrinol 152: 327-332.

27. Lasco A, Morabito N, Gaudio A, et al, 2002 Osteoporosis and beta-thalassemia major: role of the IGF-I/IGFBP-III axis. J Endocrinol Invest 25: 338-344.

28. Soliman AT, El Banna N, Abdel Fattah M, ElZalabani MM, Ansari BM, 1998 Bone mineral density in prepubertal children with beta-thalassemia: correlation with growth and hormonal data. Metabolism 47: 541-548.

29. Jin H, Ralston SH, 2005 Genetics of osteoporosis. Curr Rheumatol Rep 7: 66-70.

30. Davies JH, Evans BA, Gregory JW, 2005 Bone mass acquisition in healthy children. Arch Dis Child 90: 373378 .

31. Wonke, B, Jensen, C, Hanslip JJ, et al, 1998 Genetic and acquired predisposing factors and treatment of osteoporosis in thalassaemia major. J Pediatr Endocrinol Metab 11: Suppl 3: 795-801.

32. Brill PW, Winchester P, Giardina PJ, CunninghamRundles S, 1991 Deferoxamine-induced bone dysplasia in patients with thalassemia major. AJR Am J Roentgenol 156: 561-565.

33. Olivieri NF, Koren G, Harris J, et al, 1992Growth failure and bony changes induced by deferoxamine. Am J Pediatr Hematol Oncol: Spring 14: 48-56.

34. Chan YL, Pang LM, Chik KW, Cheng JC, Li CK, 2002 Patterns of bone diseases in transfusion-dependent homozygous thalassaemia major: predominance of osteoporosis and desferrioxamine-induced bone dysplasia. Pediatr Radiol 327: 492-497. 